\title{
Radiographic evaluation of two different implant-supported prosthesis for the edentulous mandible
}

\author{
Mahmoud A.G. Eldin \\ ${ }^{1}$ Lecturer at Faculty of Dentistry, Oral Radiology Department, Umm AlQura University, Saudi \\ Arabia. E-mail: maabdelaal@uqu.edu.sa
}

Enas T.I. Darwish

${ }^{2}$ Associate Professor at Faculty of Dentistry, Prosthetic Department, Cairo University, Egypt. E-mail: Dr_enas81@live.com

$$
\text { Received: } 10 \text { Feb. } 2020 \text { / Accepted } 15 \text { May 2020 / Publication date: } 30 \text { May } 2020
$$

\begin{abstract}
Objectives: the aim of this study is to compare hybrid implant and the conventional implant as reguard marginal bone change surrounding three implants in each group of patient. Materials and Methods: Fourteen completely edentulous patients were selected having completely edentulous upper and lower arches, divided into two groups. Group A: having hybrid dental implants-supported overdenture edentulous mandible. Group B: having conventional diameter dental implants supported overdenture edentulous mandible. In the selected groups, the implants were placed in the midline and canine regions. Radiographic evaluation was performed during the follow-up period by using panoramic radiographic records. The results were collected, tabulated, and statistically analyzed to evaluate the effect of the types of implants on marginal bone height changes. Results: data obtained from the present study showed that there was no significant difference in bone height change in both groups. Within the limitation of this study: It was concluded that: I. In elederly patients, treatment plan with three implants was suggested over two implants for suffient support and force equalization and distribution on mandibular overdenture. II. There were no significant difference between both groups treated with different dental implants diameter, and the mean marginal bone height loss was within limit.
\end{abstract}

Keywords: hybrid implants, bone change, conventional implants.

\section{Introduction}

Implant supported dental rehabilitations has been a common treatment option with favorable survival rates for replacing missing teeth and improving the quality of life of patients who are completely or partially edentulous( Saleem and Meshakm, 2011).

The use of implants with completely edentulous patients has offered a multitude of advantages such as longevity, improved function, bone preservation and better psychological results (Scarano, 2012).

A common method for retaining implant supported mandibular overdentures is individual ball abutments. However, this opinion is challenged by a number of factors including bone volume and available finances. Small diameter dental implants are considered to be a good alternative to standard dental implants.

They are cost effective, have fewer complications during implant placement and can be used in edentulous arches with minimal remaining bone in facio-lingual dimension to avoid bone graft.

Small diameter dental implants also have the advantages of single stage conventional diameter implants including short healing time, minimal postoperative discomfort, immediate restoration of mastication and esthetics for patients during the healing period (Warin et al., 2018).

\section{Aim of the study}

The aim of this study was to compare two different treatment modalities for the edentulous mandible. The first treatment plan involved a conventional diameter implant supported overdenture and the second hybrid implant-supported overdenture.

\section{Materials and Methods}

Fourteen completely edentulous patients were selected from the out patients clinic, prosthodontic department, faculty of dentistry, Cairo university to participate in this study according 
to the following criteria ; all patients were apparently in good general health, they had Angle's class I maxilla-mandibular relationship.

All patients were physically and psychologically able to tolerate conventional surgical protocol, non-smoking, their ages ranged from 40-60 years, had completely edentulous maxillary and mandibular relationship.

They had adequate inter-arch distance, sufficient bone height and width confirmed radiographically preoperatively. Patients with the following criteria were excluded from this study; presence of acute and active infection or inflammation in areas intended for implant placement, patients with apparently T.M.J. troubles or para-functional habits as bruxism, clenching were excluded. Patients with proper oral hygiene, only cooperative patients were included in the study to ensure their commitment to the oral hygiene measures and the regular follow up visit.

Intra- oral examination included visual and digital assessment were done, as well as mucosa overlying the area of prospective implants was examined (Fig. 1).

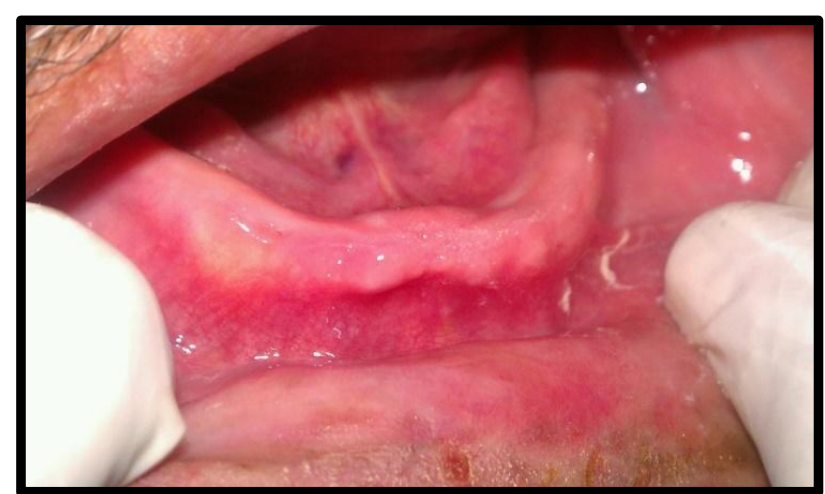

Fig. 1: Intra- oral examination of edentulous ridge.

\section{Patients grouping:}

Patients were divided into two groups according to method of treatment plane, as follows: Group A: received hybrid implants- supported mandibular overdenture. Group B: received conventional implants-supported mandibular overdenture. In each group, the implants were placed in the midline and in the canine region.

\section{Radiographic examination}

Pre-operative cone-beam computed tomography $(\mathrm{CBCT})$ was made to evaluate and plan the vertical bone height and bucco-lingual dimension available for implants installation steps of prosthetic rehabilitation (Fig. 2).

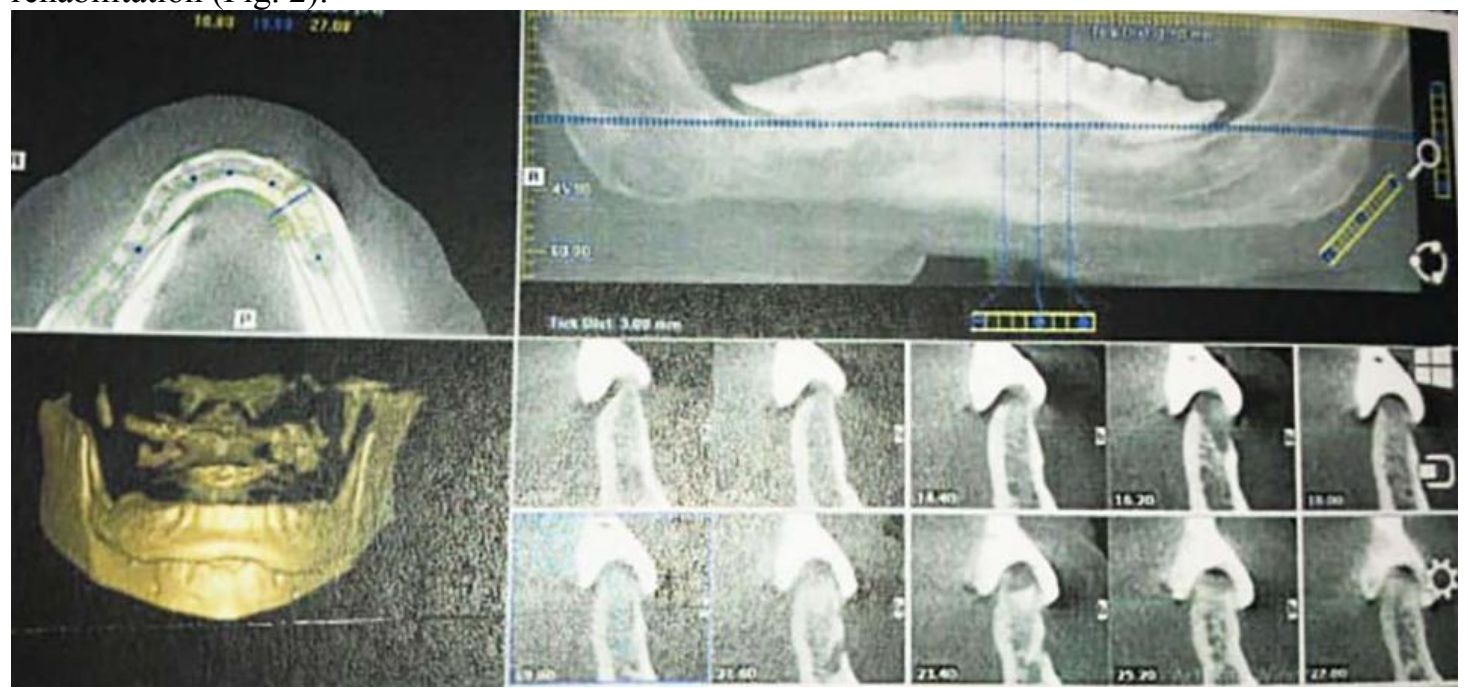

Fig. 2: pre-operative radiographic examination using cone beam. 


\section{Steps of prosthetic construction:}

Primary maxillary and mandibular impressions were made using alginate impression material (Cavex Holland B.V., P.O Box 852-2006 RW Harllem, Holland) in a suitable stock tray and poured to obtain the diagnostic casts upon which self -cured acrylic resin (Peka tray Acrostone .England) special tray were constructed. The final impression was made using rubber base impression material (Gollene Speedex Dental vertrieb G murrbtt Konster. Germany), boxed and poured in dental stone. Occlusion blocks were constructed on the master cast. Maxillary face bow record (Gnatus face bow Brazil) was made to mount the upper cast on a semi-adjustable articulator (Whip Mix \# 8500;Louisville, KY.U.S.A) the mandibular cast mounted according to a centric relation record obtained from the patient using check bite technique, and finally a protrusive record was essential to adjust the horizontal condylar guidance of the articulator. Acrylic resin teeth (Vertex quint teeth vertex. dental, Nethrland) of appropriate shape and shade were arranged following the lingualized occlusion concept and then tried in the patient's mouth. Processing the denture using heat cured acrylic resin. The denture was finished and polished then inserted and checked intraorally for extension, stability, retention, vertical dimension centric relation and esthetics, any necessaries occlusal adjustment was performed to achieve harmonious occlusion (Fig. 3).

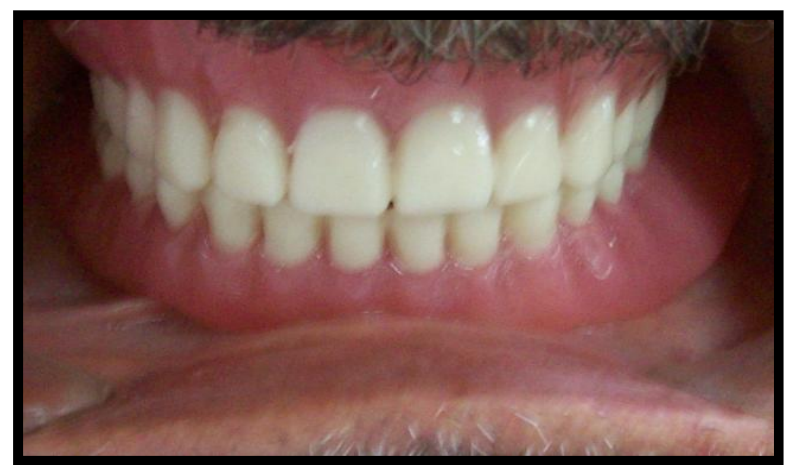

Fig. 3: Complete denture after delivery

The upper and lower waxed up dentures were duplicated into transparent heat cured acrylic resin to be used as radiographic stent (Fig.4).

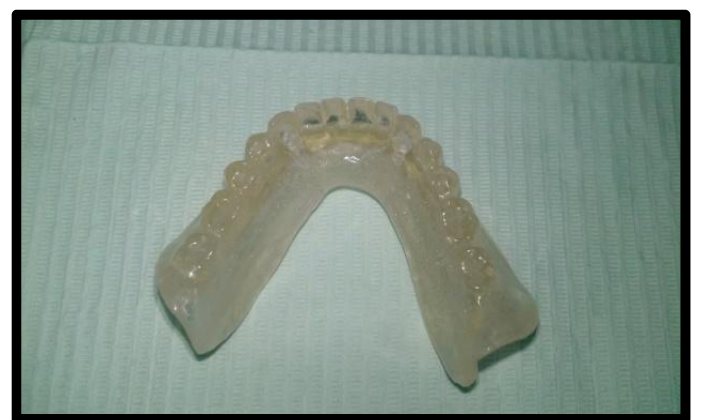

Fig. 4: radiographic stent

Two stainless balls ( $4 \mathrm{~mm}$ diameter) were fixed in the canine regions with sticky wax bilaterally in a prepared depression in the fitting surface of the lower transparent acrylic stent.

\section{Construction of surgical stent:}

The radiographic stent was modified to be used as surgical stent which is used to guide the insertion of the implants in the symphyseal area between the mental foramina. The midline was taken as a reference for positioning of the central implant, the two distal implants were marked equidistant from the midline and $5 \mathrm{~mm}$ mesial to the mental foramina, three equidistant holes were drilled in the stent opposite the proposed position of each implant. The surgical stent was then tried intra-orally. The stent was sterilized and stored in $0.2 \%$ chlorhexidine solution till the time of surgery. 


\section{Presurgical medications}

A pre-surgical medication was instructed to be under the umbrella of antibiotic to control the infection, Amoxicillin clavulanate $625 \mathrm{mg}$ was taken 24 hours before the surgery as one tablet every 8 hours, patients were asked to continue the antibiotic for one week after surgery to guard against any possible infection. They were also given an anti-inflammatory and an analgesic drug. After checking the relation of stability of the stent, infiltration anesthesia was given. The surgical stent was used for making the proposed position of the three implants on the ridge and the entry points for each implant were marked on the patient's ridge by the aid of a tissue punch (Tissue punch, 3 MESPE, Germany).

For Group A, three hybrid dental implants screw type one piece with $2.9 \mathrm{~mm}$ in diameter and $13 \mathrm{~mm}$ in length were used for each patient. A pilot drill (1.8mm diameter pilot drill, $3 \mathrm{MESPE}$, Germany) placed over the entry point and lightly pumped up and down at approximately 800- 1000 RPM with flow of copious amounts of saline solution, the implant placement was carried until protrusion of full length of the ball head from the soft tissue.

For Group B, also the surgical stent was placed in the patient's mouth (Fig. 5).

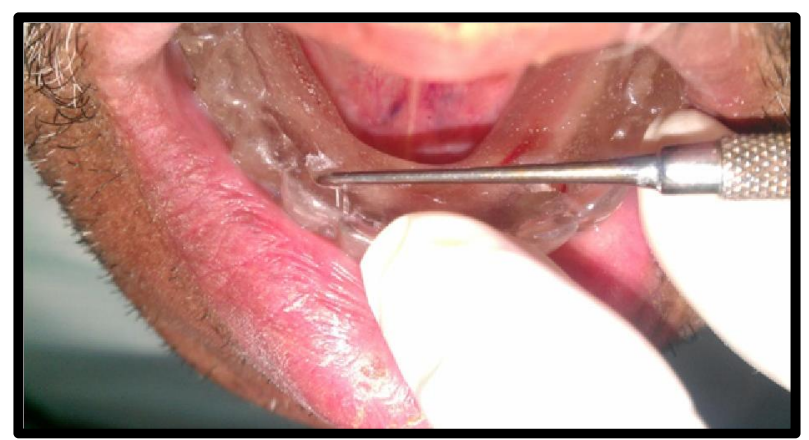

Fig. 5: surgical stent inside patient mouth

And a large surgical round bur was used to prepare holes on the ridge at each implant site. the surgical drilling was then started to prepare the sites to receive three tapered, self tapping, internally hexed implants (screw plant implant, implant direct LLC spectra-system DENTAL IMPLANT, 27030 MALIBU Hills, USA) $3.7 \mathrm{~mm}$ in diameter and $13 \mathrm{~mm}$ in length. The $2 \mathrm{~mm}$ diameter pilot drill of the implant system was used to a depth of $13 \mathrm{~mm}$ in the implant site, proper alignment and parallelism between the three implants using the paralleling tool (Fig. 6).

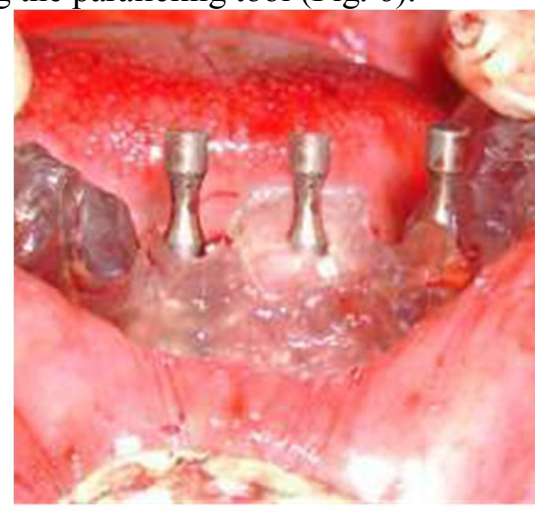

Fig. 6: Paralleling tools

Drilling was carried out intermittent strokes at a speed of 800RPM under continuous external cool saline irrigation. The ratchet was used to thread the implant in a clock wise direction until the implant top flashed completely with the bone, and then attach the implant cover screw after dropping off the included extender. The fixture mount was then unscrwed using the screw driver, finally, the fixation screws were unscrewed and the stent was removed, and the covering screws were threaded to the implant.

A post-operative digital panoramic $\mathrm{x}$-ray was taken to insure the actual sites and the parallelism between the installed implants (Fig. 7). 


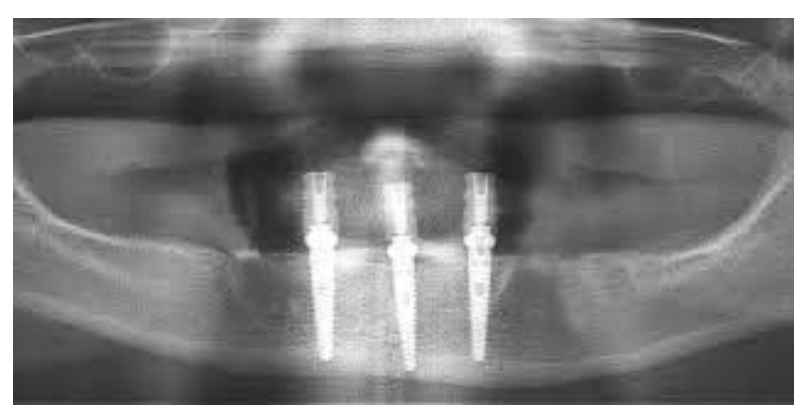

Fig. 7: post-operative panoramic $x$-ray with installed fixtures

After six weeks of implant installation in both group the denture was relined with a soft denture liner (soft lining material, Mollosil, United Kingdom), the metal housing was picked up in the fitting surface of the denture. Patients were instructed to maintain strict oral and denture hygiene measures and to keep the denture in place for the first 48 hours after placement.

\section{Evaluation of patients:}

Patients were frequently recalled for inspection, post insertion adjustment and for panoramic radiographs at the time of implants loading, as well as 3, 6, 9 months after loading.

Panoramic radiographic records were made to evaluate the implants marginal bone height changes. The patients were seated in upright position and instructed to avoid any movements during the exposure ( 20 seconds) the bone height was measured by measuring the distance from the alveolar crest to the implant apex using the linear measurements software system supplied with the panoramic radiographs. The height of bone was measured at the mesial and distal aspect of each implant and the average was calculated which was represented the bone height. The results were collected, tabulated and statistically analyzed to evaluate the effect of the two types implant used.

\section{Results}

Data were analyzed by Microsoft excel and statistical package for social science (SPSS) ver.22 The measured amount of peri-implant bone height change for the three implants (right, left, middle) at the mesial and distal aspects during the recall appointments were added and the mean values obtained for the two groups and statistically analyzed. Testing for significance within each group during follow up periods was done using Paired t-test.

Probability value of $(\mathrm{p} \leq 0.05)$ was considered statistically significant.

\section{Effect of time on bone height change around hybrid implants during follow up period.}

After three months follow up period, the calculated mean of peri-implant bone height change was $(0.17 \mathrm{~mm})$ for both mesial and distal aspects of the implants revealed insignificant statistical difference (Table 1).

After six months, the peri-implant bone height change was found $(0.47 \mathrm{~mm})$ and $(0.53 \mathrm{~mm})$ for mesial and distal revealed insignificant statistical bone height change.

At the end of the nine months follow up period bone change was $(0.1 \mathrm{~mm})$ and $(1.1 \mathrm{~mm})$ revealed significant bone height change.

Table 1: Mean values, Slandered deviation and Paired t-test of peri-implant alveolar bone height change at the mesial and distal aspects for group I during the follow up period:

\begin{tabular}{cllccc}
\hline Group I & & MD & SD & T & P \\
\hline \multirow{3}{*}{$\mathbf{0 - 3}$} & Mesial & 0.17 & \pm 0.058 & 1.72 & N.S \\
& Distal & 0.17 & \pm 0.058 & 1.74 & N.S \\
& Average & 0.17 & \pm 0.058 & 1.73 & N.S \\
& Mesial & 0.37 & \pm 0.025 & 1.93 & N.S \\
$\mathbf{0 - 6}$ & Distal & 0.40 & \pm 0.079 & 2.04 & N.S \\
& Average & 0.38 & \pm 0.52 & 2.01 & \\
& Mesial & 0.63 & \pm 0.038 & $3.7^{* *}$ & \\
$\mathbf{0 - 9}$ & Distal & 0.90 & \pm 0.072 & $3.9^{* *}$ & \\
& Average & 0.77 & \pm 0.055 & $3.74^{* *}$ & \\
\hline
\end{tabular}

M.D.: Mean difference, S.D. : Slandered deviation, P.: Probability, **: Significant, N.S.: Non-significant. 


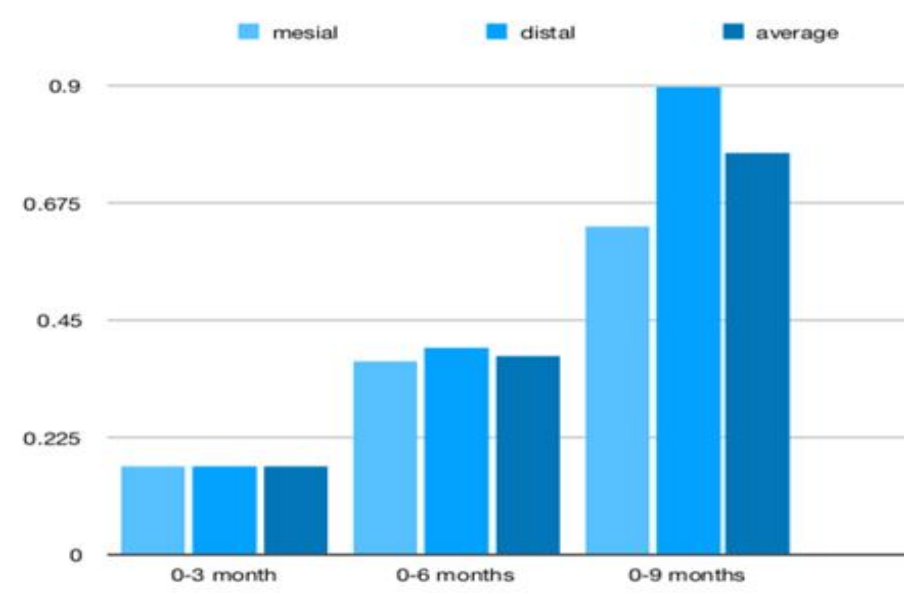

Fig. 8: Represent the effect of time on bone change in Group A.

Effect of time on bone height change around conventional implants during follow up period.

After three months, bone height change was found $(0.13 \mathrm{~mm})$ for both mesial and distal aspects revealed insignificant bone height change (Table 2).

After six months, bone height change was $(0.37 \mathrm{~mm})$ and $(0.40 \mathrm{~mm})$ for mesial and distal aspects revealed insignificant bone height change.

At the end of the follow up period, bone height change was $(0.63 \mathrm{~mm})$ and $(0.90 \mathrm{~mm})$ for mesial and distal aspects revealed significant bone height change as $\mathrm{p}$-value $<0.05$.

Table 2: Mean value, standard deviation and paired t-test of peri-implant alveolar bone height change at the mesial and distal aspects for group II during the follow up period.

\begin{tabular}{cllccc}
\multicolumn{6}{c}{ at the mesial and distal aspects for group II during the follow up period. } \\
\hline Group II & & MD & SD & T & P \\
\hline $\mathbf{0 - 3}$ & Mesial & 0.13 & \pm 0.044 & 1.67 & N.S \\
& Distal & 0.13 & \pm 0.044 & 1.65 & N.S \\
& Average & 0.13 & \pm 0.044 & 1.66 & N.S \\
$\mathbf{0 - 6}$ & Mesial & 0.37 & \pm 0.025 & 1.94 & N.S \\
& Distal & 0.40 & \pm 0.035 & 1.98 & N.S \\
& Average & 0.38 & \pm 0.03 & 1.97 & \\
$\mathbf{0 - 9}$ & Mesial & 0.63 & \pm 0.013 & $2.99^{* *}$ & $3.65^{* *}$ \\
& Distal & 0.90 & \pm 0.015 & $3.24^{* *}$ & \\
\hline
\end{tabular}

M.D.: Mean difference, S.D.: slandered deviation, P.: probability, **: Significant, N.S.: non-significant.

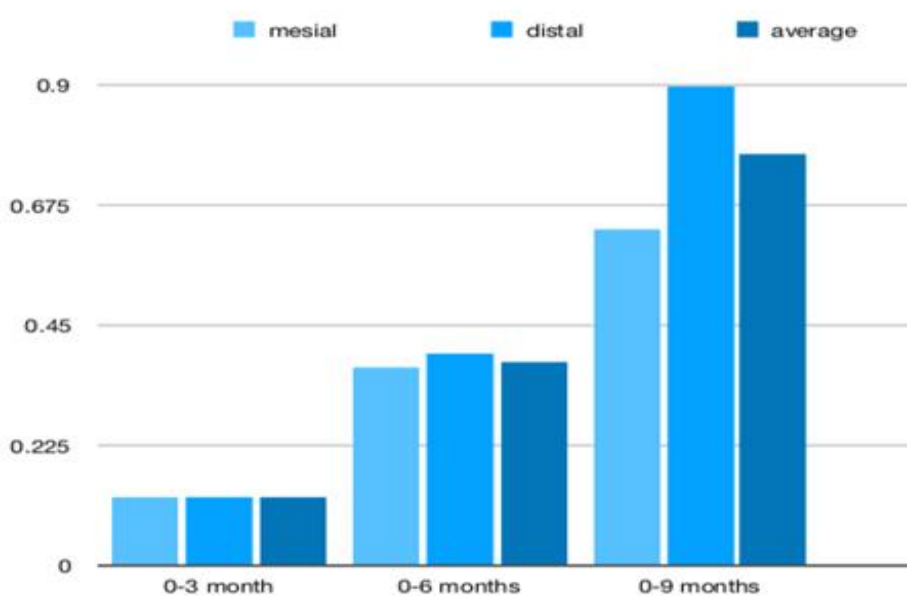

Fig. 9: Represent the effect of time on bone change in Group B. 
Effect of time on bone height change around implants of both groups during follow up period.

The data revealed that there was an insignificant difference in bone height change in both groups (Table 3).

Table 3: Comparison between the peri-implant alveolar bone change in the two groups during the follow up period.

\begin{tabular}{|c|c|c|c|c|c|c|}
\hline & & \multicolumn{2}{|c|}{ Group I } & \multicolumn{2}{|c|}{ Group II } & \multirow{2}{*}{ P-Value } \\
\hline & & MD & SD & MD & SD & \\
\hline \multirow[t]{3}{*}{$0-3$} & Mesial & 0.17 & \pm 0.058 & 0.13 & \pm 0.044 & 0.1717 \\
\hline & Distal & 0.17 & \pm 0.058 & 0.13 & \pm 0.044 & 0.1717 \\
\hline & Average & 0.17 & \pm 0.058 & 0.13 & \pm 0.044 & 0.1717 \\
\hline \multirow[t]{2}{*}{$0-6$} & Mesial & 0.47 & \pm 0.025 & 0.37 & \pm 0.025 & 0.100 \\
\hline & Distal & 0.53 & \pm 0.079 & 0.4 & \pm 0.035 & 0.1509 \\
\hline \multirow[t]{3}{*}{ 0-9 } & Mesial & 1.00 & \pm 0.038 & 0.63 & \pm 0.013 & $0.0306 * *$ \\
\hline & Distal & 1.10 & \pm 0.072 & 0.90 & \pm 0.015 & 0.292 \\
\hline & Average & 1.05 & \pm 0.055 & 0.77 & \pm 0.014 & 0.1185 \\
\hline
\end{tabular}

M.D.: Mean difference, S.D.: Standard deviation, P: Probability, **: significant, N.S.: non-significant.

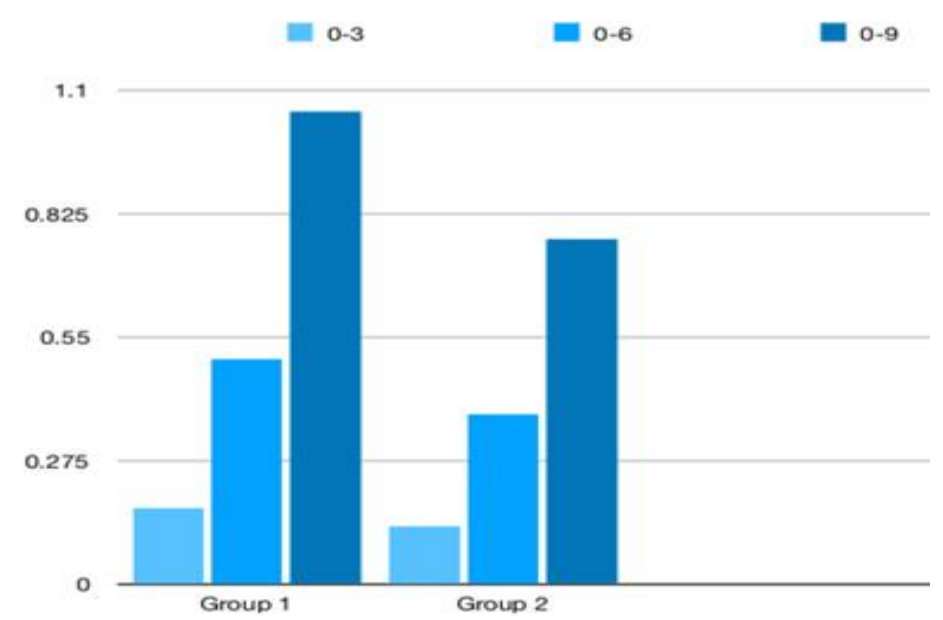

Fig. 10: Represent the effect of time on bone change in both group

\section{Discussion}

Participants in this study were selected to fulfill criteria to ensure general and oral conditions (Al-Chaarawi, 2013 and Twito and Sade, 2014) favorable for carrying out the study.

Patients selected were free from any systemic diseases that may affect the metabolic and catabolic activities (Rodrigues et al., 2014 and Rentsch-Kollar et al., 2010) to avoid adverse effect of systemic disorders on healing process, conditions of bone, and soft tissues that might affect the results of this biological study (Vieira et al., 2012) all patients in this study exhibited Angle's class I ridge relationship to avoid subjecting the implants to abnormal forces. Patients with parafunctional habits were not included to avoid TMJ disorder and muscles tenderness as a result of excessive occlusal forces (Andreitolli and Strub, 2010).

A perioperative digital panoramic radiograph was made to assist proximity to the mental foramina and to reveal any pathological lesion or remaining roots, and also to detect the quality of bone as regards to trabecular pattern and size of inter-trabecular spaces which determining the implant prognosis (Vasak et al., 2011 and Arisan et al., 2012)

Three implants were used as it was suggested that the use of more than two implants has been recommended for sufficient support and force distribution.

The interforaminal region was chosen for implant placement as it was proven to have the highest implant success rates (Benavides et al., 2012 and Ma and Payne, 2010).

For implant installation, using flapless technique in order to provide a reduced amount of tissue trauma and allows for a greater chance to preserve alveolar bone levels by not distributing the, 
periosteum layer and through improving blood supply to the implant site (Thomason et al., 2012 and Nidhin et al., 2014) this benefit were suggested to overcome the delayed mucosal wound healing side (Ismail et al., 2015 and Narby et al., 2011).

\section{Discussion of results}

Patients of both groups participated in this study achieved successful osseointegration of dental implants through regular clinical examinations and follow up radiograghs, as well as patients satisfaction as regards to function,retention and esthetics of their appliances. The success criteria for the implants are no radiolucency around the implants, no mobility, no pain, and no ongoing pathological process (Andries van der Bilt et al., 2010).

The mean marginal bone loss over the follow up period was within limit (Chreli et al., 2010), the bone resorption might be due to maturation of bone after implant placement and adaptation of bone to withstand functional forces (Jeong et al., 2011).

\section{References}

Al-Chaarawi, J., 2013.Effect of different positions of mini dental implants supporting mandibular overdentures on the denture retention. M.D.S. Thesis faculty of dentistry, Cairo University.

Andries van der Bilt, M. Burgers, F.M.C.van Kampen and M.S. Cune, 2010. Mandibular implant supported overdenture and oral function. Clin Oral Implants Res., 21(11):1209-13

Andreitolli, M.W. and J.R. Strub, 2010. Prosthodontic complications with implant overdenture; a systemic literature review. Int. J. Prosthodont, 23(3):195-203.

Arisan, V, Z.C. Krabuda, B. Piskin and T. Özdemir, 2012. Conventional Multi-Slice Computed Tomography (CT) and Cone-Beam CT (CBCT) for Computer-Aided Implant Placement. Part II: Reliability of Mucosa-Supported Stereolithographic Guides. Clinical Implant Dentistry and Related Research, 15(6): 907-917. https://doi.org/10.1111/j.1708-8208.2011.00435.x

Benavides, E., H.F. Rios, S.D. Ganz et al., 2012. Use of Cone Beam Computed Tomography in Implant Dentistry: The International Congress of Oral Implantologists Consensus Report. Implant Dent., 21(2):78-86. doi: 10.1097/ID.0b013e31824885b5.

Chreli, M.C., D. Karasoy and A.M. Kokat, 2010. A systematic review of marginal bone loss around implants retaning or supporting overdentures . Int J. Oral Maxillofacial Implant, 25(2): 266-77.

Ismail, H.A., S.A. Yousief, A.L. Mahrous, A.A. Shaban, S.N. Azzeghaiby, 2015. Clinical and radiographic evaluation of median lingualized occlusion in implant retained mandibular complete overdenture. J. Int. Oral health, 7:5-8.

Jeong, S.M, B.H. Choi, J. Kim, et al., 2011. A 1-year prospective clinical study of soft tissue conditions and marginal bone changes around dental implants after flapless implant surgery. Oral surg. Oral Med Oral Radiol., 111(11): 51-6.

Ma, S., and A.G. Payne, 2010. Marginal bone loss with mandibular two implant overdenture using different loading protocol. A systemic literature review. Int. J. Prosthodont, 23(2):117-126.

Narby, B., I.C. Bagewitz and B. Soderfeldt, 2011. Factors explaining desire for dental implant therapy: analysis of the results from a longitudinal study. Int J Prosthodont, 24(5): 437-444.

Nidhin, R., G.K. Vasunni, O. Ajay, et al., 2014. Comparative evaluation of crestal bone levels following implant placement with flap and flapless techniques in posterior edentulous areas of the mandible. An in vivo- study. J. Dent. Med. Sci., 13:95-99.

Rentsch-Kollar, A., S. Huber and R. Mericske-Stern., 2010. Mandibular Implant Overdentures Followed for Over 10 Years: Patient Compliance and Prosthetic Maintenance. Int J Prosthodont, 23(2):91-98.

Rodrigues, S.J., M. Mundathaje, M. Raju, S. Qureshi, 2014. Three dimensional imaging in implant assessment for the prosthodontist utilization of the cone beam computed tomography. Int. J. prosthodontic Res., 4:23-33.

Saleem, M., and R.A. Meshak, 2011. Prosthetc management of edentulous mandible using endoesseous implants and overdentures. J. contemp Dent. Pract., 12(2):135-7.

Scarano, A., 2012. Small-diameter dental implants. An adjunct for retention, stablty and comfort for the edentulous patients. J. Osseointegration, 3(4):48-50. 
Thomason, J.M., S.A. Kelly, A. Bendkowski and J.S. Ellis, 2012. Two Implant Retained Overdentures-A Review of the Literature Supporting the McGill and York Consensus Statements. J Dent., 40(1):22-34. doi: 10.1016/j.jdent.2011.08.017. Epub 2011 Sep 3.

Twito, D., and P. Sade, 2014. The effect of cigarette smoking habits on the outcome of dental implant treatment. Peer J.2: 546-9.

Vasak, C., G. Watzak, and A. Gahleitner, 2011. Computed tomography based evaluation of template (Nobel guide). Guided implant position a prospective radiological study. Clin Oral Implants Res., 22 (10): 1157-63.

Vieira, R. A., A. C. M. Melo, L.A Budel, J. C. Gama, I. A. de Mattias Sartori and G. Thomé, 2012. Benefits of Rehabilitation With Implants in Masticatory Function: Is Patient Perception of Change in Accordance With the Real Improvement? J Oral Implantol., 40(3):263-9.doi: 10.1563/AAID-JOI-D-11-00208

Warin, P., P. Rungsiyakull, C. Rungsiyakull and K. P. Khong, 2018. Effect of different numbers of mini-dental implants an alveolar ridge strain distribution under mandibular implant retained overdenture. J. prosthodont Res., 62:35-43. 